\title{
La diferenciación socio-espacial en la ciudad de Burgos durante los años de la posguerra
}

\author{
Pedro díaz Miguel
}

\section{INTRODUCCIÓN}

\subsection{La diferenciación interna en las ciudades}

Son numerosos los análisis de las poblaciones en el interior de las ciudades que han demostrado que su distribución espacial no es socialmente homogénea. Esta distribución de la población no responde a la casualidad, sino que se debe a los diversos niveles de segregación existentes y a los distintos grados de marginación social entre las diversas zonas de la ciudad (GONZÁLEZ GONZÁLEZ, M. J., 1997, pág. 51). Es tan evidente esta diferenciación ínterna que se puede decir que ha sido prácticamente una constante universal (PUYOL, R., ESTÉBANEZ, J., MÉNDEZ, R., 1992, pág. 510).

Con la llamada Revolución Industrial surge lo que podemos considerar la segregación socioespacial urbana a gran escala. Dicha revolución trajo consigo cambios gigantescos en las sociedades donde se ha desarrollado. Tres hechos claves pueden dar significado a la afirmación anterior:

a) Aumento general de la población a cifras nunca vistas ni pensadas.

b) Cambio profundo en la estructura productiva de las sociedades: el dominio del sector primario agrícola da paso al dominio del sector secundario industrial para llegar a una tercera fase de dominio del sector terciario.

c) Nueva estructura de los asentamientos humanos. El predominio de asentamientos pequeños y dispersos da paso a un número mucho menor de asentamientos, pero más grandes y dominantes. Es la irrupción mayoritaria de las ciudades. 
A raíz de estos cambios se aprecian en las ciudades transformaciones llamativas. Aparece con fuerza la separación de usos (industrial, servicios, residencial) y el transporte masivo de personas y mercancías. Dentro de las amplias y nuevas zonas residenciales se aprecia claramente diferencias llamativas. Ello no es otra cosa que el reflejo de la sociedad donde se desenvuelven las ciudades, en las cuales existen grupos o clases favorecidas y dominantes y clases desfavorecidas y sometidas.

Es en el campo de la sociología donde empiezan a surgir estudios relacionados con los cambios urbanos acaecidos, haciendo hincapié en las claras diferenciaciones existentes en el seno de las ciudades. La Escuela de Chicago surge en dicha ciudad en la década de los años veinte del presente siglo. Esta Escuela sociológica tiene en E.W. BURGESS y R.D. MCKENZIE sus principales representantes. Estos sociólogos aplican a las comunidades humanas una serie de términos propios de los estudios biológicos. Los conceptos fundamentales usados en esta Escuela son los de competencia personal, principio de dominación e invasión-sucesión.

Con los planteamientos anteriores, se pasa a analizar la distribución de las comunidades en las ciudades. Así, surgen conceptos como competencia por el espacio, principios económicos sobre el suelo, el dominio urbano del Distrito Comercial Central.

Una de las manifestaciones concretas de la teoría general antes expuesta es elaborada por Burgess, quien distribuye la ciudad en anillos concéntricos, siendo el centro de los círculos el Distrito Comercial Central. Hoyt continúa en la línea anterior, pero establece zonas sectoriales, no circulares.

A pesar de la gran importancia e influencia que tuvieron los planteamientos de la Escuela de Chicago, no escaparon a la crítica. Como más significativas, podemos señalar la de ALIHAM sobre la posición dualista de los ecólogos urbanos. GETHYS criticó la gran importancia dada al determinismo económico. FIREY, junto con sus críticas, introduce factores de tipo cultural.

En las décadas de los años cincuenta y sesenta en los Estados Unidos se retoma con fuerza el análisis interno de las ciudades, con las llamadas Áreas Sociales. Sus impulsores son SHEVKY y BELL. Su planteamiento busca encontrar la diferenciación interna de la ciudad de acuerdo con tres índices principales que se deducen de las características contenidas en los Censos de Población. SHEVKY los llamó rango social, urbanización y segregación y BELL estatus económico, familiar y étnico. 
Para ellos, la complejidad de la organización productiva produce una mayor movilidad en la población, que origina una redistribución en el espacio y se traduce en el aislamiento de grupos humanos. Las tres dimensiones planteadas se miden con una serie de indicadores. El rango social por el porcentaje de obreros manuales respecto a la población activa total $y$ el porcentaje de población adulta con menos de nueve años de estudios primarios. El estatus familiar o urbanización se mide por la tasa de natalidad, el porcentaje de mujeres trabajando fuera de casa y el porcentaje de viviendas unifamiliares sobre el parque total. La segregación o estatus étnico se mide por el porcentaje de grupos étnicos con respecto a la población total.

Un nuevo empuje, con algunos cambios sobre estos planteamientos de Áreas Sociales es el dado por MacELRATH, que se aparta del determinismo económico simple. Marca a la industrialización y la urbanización como los dos grandes ejes de los que nace la diferenciación residencial. Hay que apuntar el feliz encuentro de la ecología urbana con la técnica estadística factorial, surgiendo de él la llamada ecología factorial. Se cita a G. SWEETZER como su iniciador con su trabajo sobre Helsinki en 1960. D. TIMMS logra importantes resultados dentro de esta tendencia, marcando los principales contenidos en una teoría de la diferenciación residencial (TIMMS, D., 1971).

En resumen, podemos decir que la ciudad se ha convertido en un mosaico social donde cada parte tiene unas caracteristicas específicas. Pero las diferencias existentes son muchas veces excesivas indicando una injusta organización del espacio urbano (PRECEDO, A.; RODRÍGUEZMARTÍNEZ, R.; VILLARINO, M., 1989, pág. 173).

Por ello se hace imprescindible el estudio más exacto posible de la distribución espacial de la población de una ciudad si queremos analizar realmente el entramado social de la misma. No conocer correctamente esta segregación socioespacial nos llevaría a una apreciación de la ciudad sesgada y lejana de la realidad.

\subsection{Planteamientos básicos}

Tres presupuestos básicos han articulado la investigación realizada (el trabajo cobra su pleno sentido dentro de otro más amplio que trata de 
descubrir la evolución de la segregación socioespacial dentro de la ciudad de Burgos ${ }^{1}$ entre los años 1940-1990). En primer lugar, conocer las pautas de la diferenciación socio-espacial de Burgos en los años de la posguerra y los factores explicativos de la segregación subyacente. Para ello, y en segundo lugar, usaremos como fuente básica de información el Padrón Municipal de Habitantes (PMH) de 1945. Y el tercero es que utilizaremos la técnica estadística del análisis factorial.

\subsection{Burgos en la Posguerra}

Burgos era al acabar la Guerra Civil una ciudad que contaba según el Censo con algo más de sesenta mil habitantes. Ello le da un estatus de ciudad intermedia dentro del rango de las ciudades españolas. La capitalidad provincial era su principal motor de actividad, junto con una importante función militar y religiosa. La actividad industrial quedaba en muy segundo plano. Poco a poco se iba recuperando de los cambios sufridos durante la contienda debido a su papel de capital del bando franquista, volviendo a su papel de ciudad capital de provincia.

El caserío de la ciudad es cifrado en poco más de diez mil viviendas, escasas para el volumen de población existente. Ello nos habla de penuria, hacinamiento y falta de residencia estable, para un colectivo importante de la población. El mismo Ayuntamiento tiene conciencia de ello, pues habla de la necesidad de construir tres mil viviendas para solucionar el grave problema acarreado por su falta ${ }^{2}$.

Sobre esta ciudad y en estas fechas cercanas a la terminación de la contienda, vamos a profundizar sobre su población y su distribución interna.

La ciudad, que había nacido en un cerro testigo (siglo $\mathrm{x}$ ), pasa luego a ocupar su ladera (siglos $x$ y $x \mathrm{l}$ ), posteriormente se asienta en el llano junto al río Arlanzón (siglos XII, XIII, XIV y XV), se consolida y florece (siglo $x V I$ ), decae y se recupera (siglos XVII y XVIII), conoce el crecimiento de su arquitectura civil (siglo $\mathrm{xIX}$ ) y sufre cambios importantes,

\footnotetext{
Al coincidir el nombre de la capital con el de la provincial, usaremos el nombre de Burgos para referirnos a la ciudad únicamente, con ánimo de simplificar la lectura. Cuando se hable de la provincia se dirá expresamente.

2 Pleno Municipal de 10-7-1942, folios 250-253.
} 
debido a su crecimiento, durante la primera parte del siglo $\mathrm{xx}$. Llega a 1945 con la fisonomia que nos da el plano de la figura 1 . Se puede apreciar que la ciudad, pese a su fisionomía lineal, aún guarda equilibrio entre las dos zonas divididas por el río Arlanzón. Queda ajena al conjunto la Barriada Militar, excéntrica en la zona este. También se puede apuntar que el centro urbano consolidado en el devenir histórico, léase Plaza Mayor y Plaza del Cid van quedando fuera del centro del imaginario círculo que puede resultar la ciudad. Ésta empieza a romper la dinámica urbana de equilibrio hacia la zona noroeste, los llamados Vadillos.

Podemos decir que Burgos era algo muy alejado de la realidad actual. Su evolución había sido lenta, en líneas generales hasta hacía muy pocos años. Los cambios radicales experimentados años más tarde, sobre todo en los años sesenta, transformarían totalmente su fisionomía. Surgirían nuevos y populosos barrios, como el de Gamonal y la población sería triplicada.

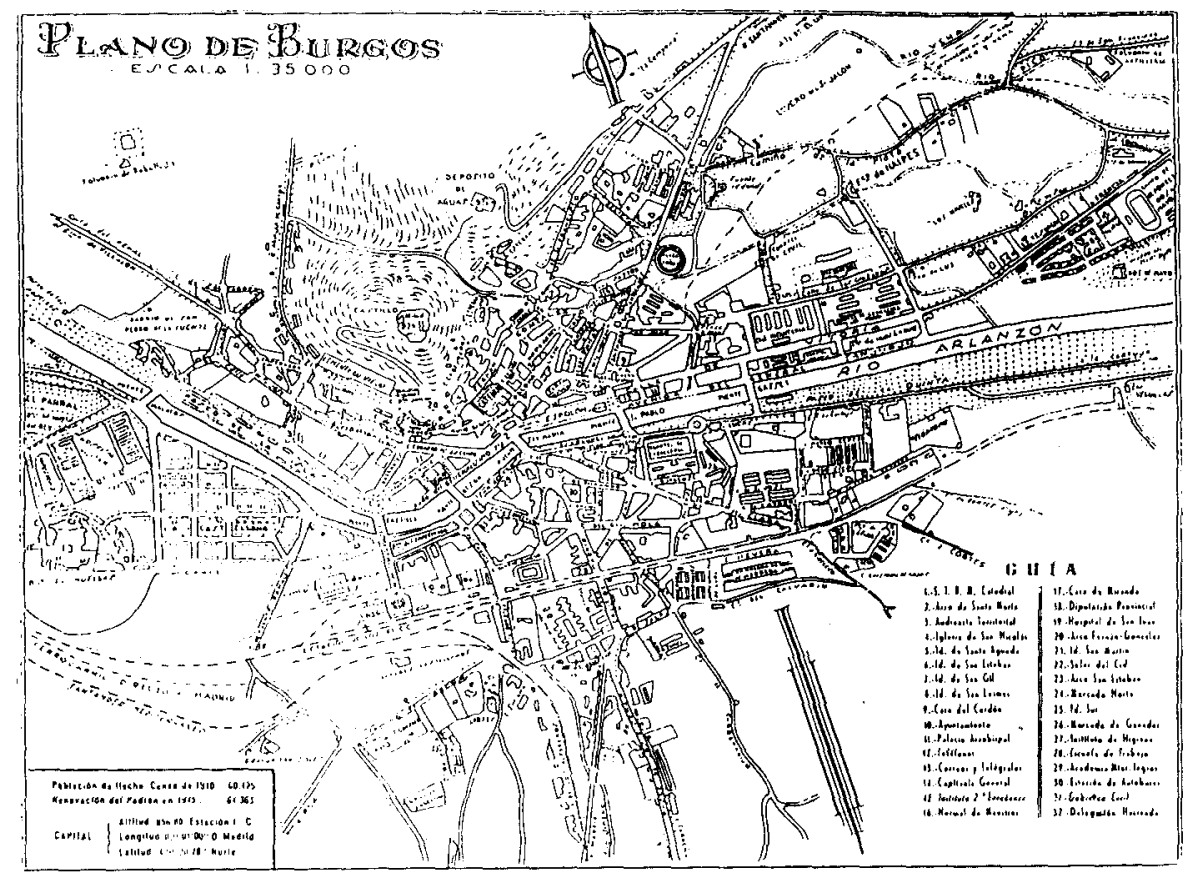

Figura 1. Plano de la ciudad de Burgos (1945). Fuente: Boletín de Estadística Municipal, 1945. 


\section{LA PROBLEMÁTICA DE LA RECOGIDA DE LA INFORMACIÓN. EL PMH DE 1945}

\subsection{La elección del PMH como fuente básica de información}

El padrón municipal de habitantes como fuente de estudio ha sido usado en numerosas ocasiones dentro del campo de la Geografía Urbana. Es sumamente interesante el uso de esta fuente, ya que reúne unas cualidades difíciles de encontrar en otras.

Hemos elegido el año de 1945 porque nos parecía una fecha indicada para conocer la realidad social de una ciudad al inicio de una época claramente diferenciada con la anterior. La Guerra Civil supuso un corte en el discurrir histórico del país. Tras ella, un nuevo período se abre en la historia española.

No hemos elegido como fuente el PMH de 1940 por considerar esta fecha demasiado cercana al final de la Guerra Civil. Durante la misma, la ciudad fue capital del bando franquista, lo que distorsionó totalmente su vida cotidiana. BARBANCHO señala que en los censos de 1940 se constatan numerosos irregularidades, sobre todo a causa de la reciente Guerra Civil (BARBANCHO, A.B, 1967, pág. 30). ÁLVAREZ-CIENFUEGOS también señala que los Censos de 1940 muestran errores, fundamentalmente a causa de las cartillas de racionamiento, que originaron inscripciones dobles (ÁLVAREZ-CIENFUEGOS RUIZ, F.J., 1984, pág. 108).

Según N. GONZÁLEZ, se puede decir que la población de Burgos al término de la Guerra Civil era de 115.000 habitantes, muy por encima de los 40.000 burgaleses que se albergaba la ciudad al iniciarse las hostilidades en 1936 (GONZÁLEZ, N., 1958, pág. 210).

Estas distorsiones pensamos que se encuentran corregidas, o por lo menos mitigadas, en 1945, por lo que los resultados obtenidos seguramente son mucho más acordes con la realidad de la ciudad.

\subsection{La población de la ciudad según el Censo de 1940}

Como los Censos de población son realizados cada diez años, nos hemos visto obligados a recoger los resultados del primero, hecho tras la Guerra Civil. Sus datos generales y dinámica poblacional no deberían de estar muy alejados de la población que nosotros analizamos de 1945.

Presentamos las líneas generales de las características de la población mostradas por el Censo con el objetivo de conocer las cifras más importantes a la vez que nos permite contrastar la poca operatividad dentro de la ciudad. 
Según esta fuente de información, su población llegaba a 60.425 habjtantes y su distribución por edad y sexo o pirámide poblacional viene recogida en la figura 2.

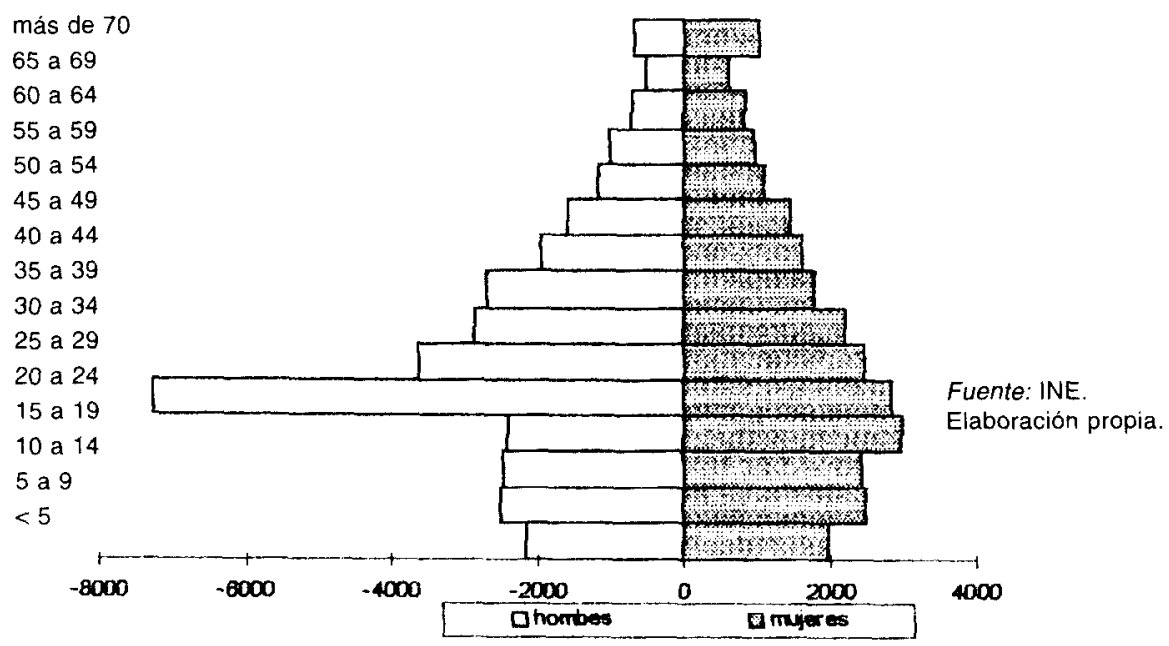

Figura 2. Distribución de la población de Burgos (1940) por edad y sexo.

Para entender correctamente lo que ocurre con la población de la ciudad, hemos de apuntar una serie de datos que se recogen en el Resumen del Padrón Municipal de 31 de diciembre de $1940^{3}$. Del total de población recogemos, en el cuadro 1, los grupos de personas que viven en el llamado régimen colectivo:

CUADRO 1. DISTRIBUCIÓN DE LA POBLACIÓN DE BURGOS (1940) EN RÉGIMEN COLECTIVO

\begin{tabular}{|c|c|}
\hline Ejército de tierra & 7.267 \\
\hline Policía armada & 48 \\
\hline Guardia Civil & 80 \\
\hline Carabineros & 8 \\
\hline Hospitales & 175 \\
\hline Asilos & 390 \\
\hline Hospicios & 1.052 \\
\hline Cárceles & 5.235 \\
\hline & 14.255 \\
\hline
\end{tabular}

3 Archivo Municipal de Burgos. Sección Estadística 1899. 
Este listado es sumamente interesante, ya que nos muestra aspectos claves para entender lo que realmente era la situación demográfica de la ciudad. El listado nos confirma que casi un cuarto de la población vive en colectividad, voluntaria en unos casos, no voluntaria en la mayoría. Muchas de las cifras del listado derivan de la reciente Guerra Civil.

GARCIAA BALLESTEROS señala que la cifra de 1940 para Guadalajara también está hinchada por motivos semejantes a los de Burgos: elevado número de militares, muchos presos y posibles falsas inscripciones (GARCÍA BALLESTEROS, A., 1978, pág. 277).

El alto volumen de población militar viene dado por los muchos cuarteles existentes en la ciudad y por la capitanía del bando nacional, ostentada por la ciudad durante la guerra. El elevado número de presos existentes también son el resultado de la reciente guerra. El número de asilados y hospicianos hablan por sí solos de la penuria existente.

Estas cifras son la causa fundamental de la distorsión de la pirámide expuesta, ya que los componentes militares son todos masculinos, en edades muy concretas y los presos también son igualmente del mismo sexo, en edades más heterogéneas, aunque con predominio de las edades medias. El resto de esta población sería de componente mixto.

Con estas puntualizaciones, podemos decir que la pirámide de la ciudad nos muestra una población en el primer grupo de edad, resultado de la disminución de nacimientos a causa de la reciente Guerra Civil.

A partir de los 20 años, se da un desproporcionado predominio masculino, siendo muy llamativo del grupo de edad de 20 a 24 años. Ello es debido, fundamentalmente, a la gran cantidad de soldados existentes en los muchos cuarteles de la ciudad. Este hecho confiere a la pirámide poblacional de un componente que rompe el equilibrio de su estructura general. Aunque en disminución, los grupos siguientes, hasta los 50 años, siguen conociendo un predominio masculino, fruto de lo anteriormente dicho y de la población reclusa censada en la ciudad, eminentemente masculina. Sólo a partir de los cincuenta se aprecia el normal predominio porcentual femenino de las pirámides poblacionales.

Con los datos, que hemos obtenido de nuestro muestreo del PMH de 1945 , hemos elaborado una nueva pirámide poblacional, cuyo perfil viene reflejado en la figura 3. 


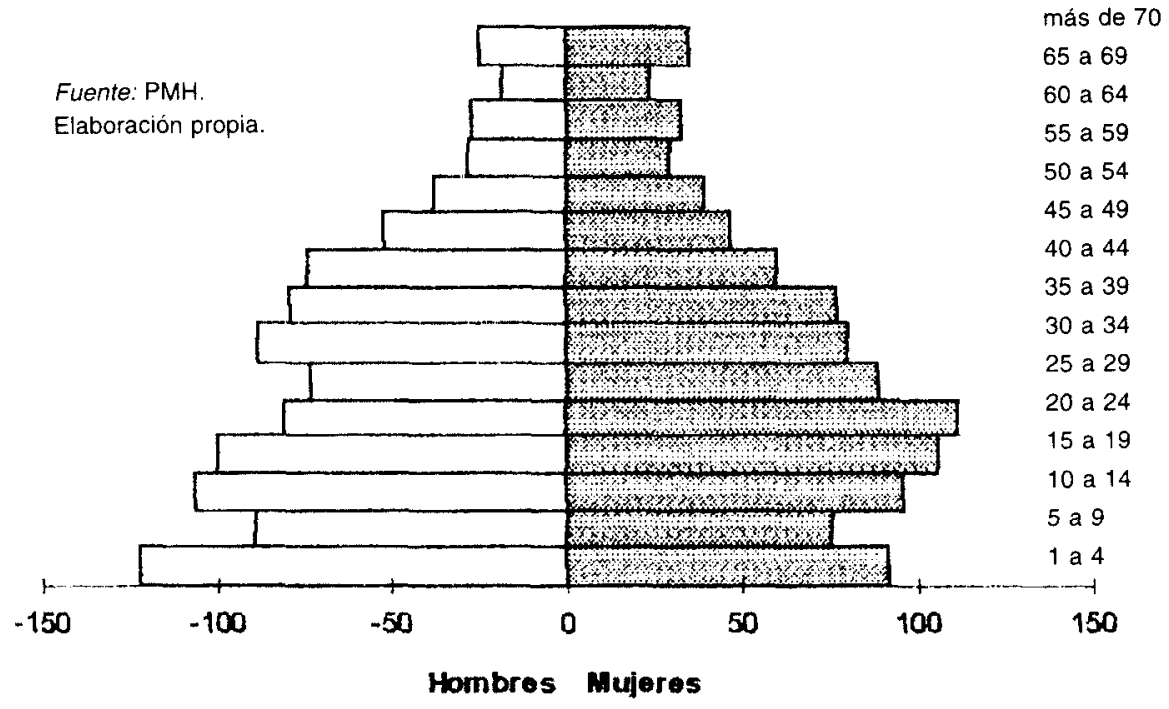

Figura 3. Distribución de la población de Burgos (1945) por edad y sexo.

Como vemos, las «distorsiones» producidas por el alto número de personas viviendo en régimen colectivo se han corregido. Con ello tenemos una idea más exacta del perfil demográfico de la ciudad. El predominio masculino según el Censo de 1940 en los grupos de edad de 20 a 24 años y de 25 a 30 se ve ahora variado, apreciándose el predominio femenino en estos grupos de edad, fruto seguramente de las secuelas de la G!ıerra Civil. Los demás grupos de edad están bastante equilibrados. Se aprecia una recuperación de la población tras la Guerra Civil en el grupo de menor edad.

2.3. El PMH como fuente con gran importancia para estudios de ecología factorial

Es un problema importante el que los padrones de esas fechas no se encontraban, lógicamente, informatizados, por lo que su vaciado para el estudio es una tarea que requiere cuidado y horas de dedicación.

J. GÓMEZ y C. BEL señalan al efecto que ha sido preciso esperar en España a los últimos años para que los servicios de estadística municipales se modernizaran para abordar de forma fructífera su estudio (GÓMEZ 
FAYREN, J.; BEL ADELL, C., 1987, pág. 241). Nosotros tuvimos que acometer esta tarea con un padrón no informatizado.

EI PMH recoge a la totalidad de la población residente en la ciudad. Las encuestas se realizan por viviendas, coincidiendo prácticamente siempre con una única familia. La recogida de la información tiene un importante grado de fiabilidad. En 1945 se ubica a la población en sus calles y números de residencias, se distinguen las unidades familiares, el sexo de cada miembro de la familia, la edad, estado civil, analfabetos, lugar de nacimiento, años de residencia en Burgos capital, profesión. En esta recogida de datos, bastante completa para el objetivo que nos proponemos, no se recogen algunos que pudieran haber sido de gran interés, como pueden ser la renta familiar y el tamaño de la vivienda.

EI PMH permite una máxima desagregación de la población según distritos y secciones. Sobre el tamaño de la unidad básica en el análisis de ecología factorial existe casi unanimidad, entre los autores que han tratado el tema, sobre que la sección censal es la ideal. Unidades mayores diluirian la especificidad de cada zona y las menores son poco operativas. Para el objetivo de nuestra investigación, hemos seleccionado como unidad espacial de recogida de información la sección censal, tal como habia sido delimitada administrativamente en el municipio. No obstante, hemos debido realizar algunas correcciones. Al ser un análisis de muestreo, las muestras deben tener suficiente volumen de población como para que resulten representativas, por lo que hemos decidido unir aquellas secciones contiguas que recogian muy escaso número de habitantes. También existen secciones que reúnen los habitantes de una calle en una de sus manos y la siguiente sección la otra. Hemos decidido homogeneizarlas, pues pensamos que pocas diferencias sociales pueden existir entre ambas, lo que a su vez facilita la cartografía. El resultado final es que hemos subdividido la ciudad en 36 zonas, 10 que nos da una media de 1.678 personas por zona si las dividimos por la población total (con toda la población colectiva), o de 1.279 si restamos la población en régimen colectivo, cifra esta última que se acerca más a la realidad.

\subsection{Recogida de información. El muestreo}

Enfrentarse con una fuente como el $\mathrm{PMH}$ ha requerido una serie de pasos y decisiones importantes. A priori, se podian establecer las pautas a 
seguir, pero una vez iniciada la recogida de datos se han tenido que ir solucionando diversos problemas. Tres fases podremos distinguir en este apartado: decisión del tamaño de la muestra/datos a recoger, recogida de datos cualitativos y transformación de estos datos en cuantitativos a la hora de volcarlos en el programa informático.

Decidimos que el tamaño de la muestra fuera del $20 \%$ de la población recogida en el PMH. Consideramos que es lo suficientemente representativa para el objetivo propuesto. A. MORENO usa también este porcentaje en su trabajo basado en la explotación del PMH de Carabanchel en 1975 (MORENO JIMÉNEZ, A., 1987, página 472). Igualmente A. CAÑAMERO realiza un muestreo aleatorio del $20 \%$ del PMH para su trabajo sobre Alza (CAÑAMERO, A., 1988, páginas 329385).

Elegimos para ello las familias cuya numeración en el PMH terminara en 0 y 5 , aunque otros dos números cualquiera nos hubieran servido. Aquí hay que apuntar el problema que hubiera conllevado el coincidir dichos dos finales de cifra con lugares como cuarteles, cárcel o seminario, donde se encontraban miles de personas encuadradas (prácticamente todos varones). Creemos que ello hubiera distorsionado la visión del mosaico urbano que nos proponemos.

En la recogida de datos nominales hemos mantenido todas las denominaciones que existen en el PMH. En la mayoría de los apartados, los datos están claramente identificados. Solamente en el apartado de profesión se aprecia que recoge datos para todos los habitantes, nombrándolos por su actividad laboral y, en su defecto, estudiantes, menores, sus labores, inútiles o nada. María J. JIMÉNEZ señala también problemas parecidos a la hora de usar el PMH como fuente de información social (JIMÉNEZ, MARÍA, J., 1990, págs. 61-66).

Por ello, este apartado en el que se recoge la pertenencia de cada persona a una profesión o actividad económica ha sido el más complicado a la hora de las agrupaciones, lo que siendo de gran interés en un estudio de esta naturaleza, resulta, sin duda, problemático.

En el cuadro 2 reflejamos las categorias resultantes inicialmente. El estudio de la diferenciación socioespacial de la ciudad aconsejó el tratamiento de las más representativas. 


\section{CUADRO 2. VARIABLES RECOGIDAS DEL PMH (1945) Y SU CATEGORIZACIÓN ESPECÍFICA}

1. Situación (SITU). 1,2,3.., según zona estipulada. Normalmente coincide con la sección.

2. Sexo (SEXO). 1: Hombre, 2: Mujer.

3. Edad (EDAD). 1, 2, 3..., la que se tenga.

4. Lugar de Nacimiento (LUNA). 1. Burgos capital.

2. Burgos provincia.

3. Castilla-León, más Cantabria y Rioja.

4. Madrid-Barcelona.

5. Resto del Estado.

6. Extranjero.

5. Estado civil (ESCI).

7. Sin datos.

1. Soltero.

2. Casado.

3. Viudo.

4. Otros.

5. Sin datos.

6. Estudios (ESTU).

1. Alfabetizado.

2. Analfabeto.

3. De 1 a 6 años (sin escolarizar).

4. Sin datos.

7. Profesiones (PROF).

1. Jornaleros.

2. Artesano, autónomo.

3. Trabajadores manuales de la industria y construcción.

4. Sector terciario no incluido en otro apartado.

5. Propietario, rentista, industrial.

6. Profesiones liberales, procurador, magistrado.

7. Agente, ATS, perito.

8. Profesor, maestro, catedrático.

9. Agregado, funcionario, guardia civil, policía.

10. Militar.

11. Paro, nada.

12. Jubilado, pensionista.

13. Sus labores.

14. Religioso, sacerdote.

15. Sirvienta, asistenta (internas).

16. Menor para trabajar.

17. Estudiante.

18. En la mili.

19. Labrador, agricultor, ganadero.

20. Sin datos.

21. Inútil, inválido.

8. Tiempo de residencia en Burgos capital (TIEM). 1,2, 3.., los años de residencia de los emigrados.

97. Sin datos, pero nacido en la capital.

98. Nacido en Burgos capital y residente siempre.

99. Sin datos. 


\section{LA ECOLOGIA FACTORIAL DE LA CIUDAD DE BURGOS EN 1945}

\subsection{La ecología factorial}

El análisis factorial es una técnica estadística usada en numerosos trabajos de ecología humana, aunque también existen trabajos geográficos no específicamente urbanos que usan de esta técnica estadistica singular (ÁVILA TAPIES, R., 1993, pág. 111).

La aplicación de esta técnica en el estudio de la diferenciación interna de la ciudad comenzó a usarse en el mundo anglosajón, desde comienzo de los años sesenta. Su posterior difusión en nuestro país tuvo lugar con varios años de desfase. Existen numerosos trabajos en el ámbito del Estado español, como nos muestra M. ${ }^{a}$ A. DÍAZ hasta 1989 (DÍAZ MUÑOZ, M. A., 1989, págs. 115-133) existiendo también trabajos posteriores (LEONARDO AURTENETXE, J.M., LAVÍA MARTÍNEZ, C., 1990, págs. 97-110).

El objetivo fundamental del análisis factorial es resumir un número relativamente grande de variables en unas "supervariables" o factores, sin que se pierda mucha información. Es la sintetización de la información que nos permite una mayor operatividad. Las ideas fundamentales de todo este proceso estadístico y su aplicación en Geografía la podemos encontrar en SANTOS PRECIADO, J.M. (1991, págs. 13-78).

En resumen, consideramos que esta técnica perfectamente aplicable para conseguir los objetivos que nos proponemos.

\subsection{Las unidades espaciales del análisis.}

Sobre el plano de la figura 1, hemos trazado las diversas zonas que servirán de base para nuestro estudio. Los ocho distritos administrativos en que es dividida la ciudad se representan en la figura 4: Espolón (1), zonas 1, 2, 3 y 4, Casa del Cordón (2), zonas 5, 6, 7 y 8, Catedral (3), zonas 9, 10, 11,12 y 13 , Castillo (4), zonas 14,15 y 16, Los Vadillos (5), zonas 17, 18, $19,20,21,22$ y 36 , Vega (6), zonas $23,24,25,26$ y 27, La Quinta (7), zonas $28,29,30$ y 31 ,y la Estación (8), zonas $32,33,34$ y 35 . Las zonas 22,31 y 36 tienen un trazado adaptado debido a que recogen población censada en los barrios de la ciudad con claro matiz rural (Villímar, Cortes, Villatoro), separados del casco urbano por franjas agrícolas, a lo que deben su amplitud en el plano. De los distritos señalados, podemos decir que los 
tres primeros, Espolón, Casa del Cordón y Catedral conforman el centro de la ciudad de entonces, fruto de su evolución anterior. Es aquí donde se concentran las principales instituciones. El distrito Castillo recoge la parte más antigua de la ciudad existente. Integra las laderas del cerro testigo en donde se asentó el castillo que dio origen a la ciudad, junto al cual se ubicaron los primeros grupos de viviendas. El distrito de los Vadillos se identifica con el "ensanche" reciente de Burgos, por donde se va produciendo su crecimiento más importante. Al lado sur del río Arlazón encontramos el distrito de Vega, donde se trata de llevar a cabo el centro social y comercial de esta zona de la ciudad, con una estación de autobuses recientemente inaugurada y un trazado de nuevas y anchas alineaciones para las calles principales. Los distritos de la Estación y la Quinta son periféricos al distrito de Vega. El primero recoge esencialmente la gran superficie ocupada por el ferrocarril, como la estación, terrenos y locales adyacentes. La Quinta reúne un caserío periférico que se va acercando a las laderas de los cerros situados al sur de la depresión donde se encuentra la ciudad.

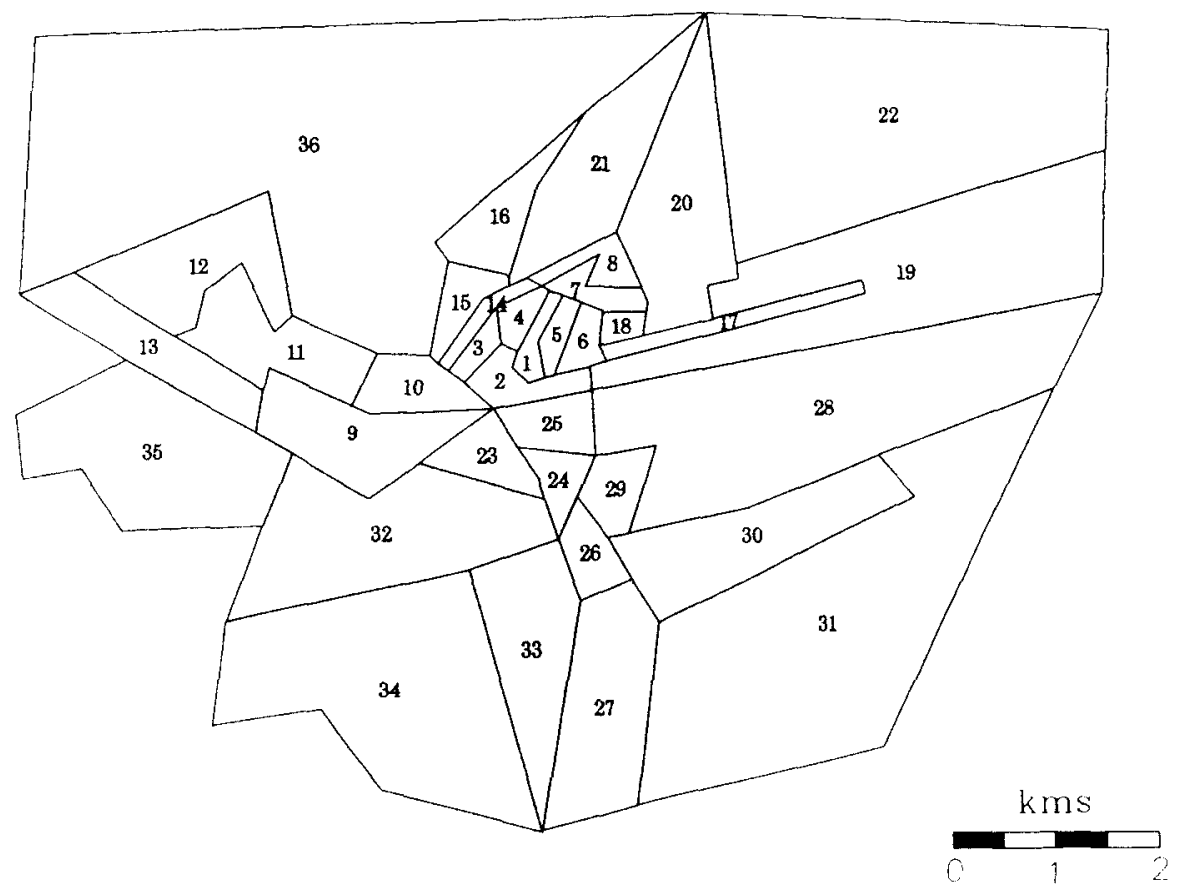

Fuente: Elaboración propia

Figura 4. ldentificación de las secciones censales. Burgos, 1945. 


\subsection{Las variables del análisis}

Un paso importante en todo análisis de ecología factorial urbana es la selección y estudio de las variables representativas de la diferenciación social. Es importante realizar bien la elección, ya que una información redundante o incorrecta lastraría los resultados obtenidos (JIMÉNEZ BLASCO, B.C., 1984, págs. 167-183).

Las variables elegidas para realizar nuestro análisis factorial han sido recogidas en el cuadro 3 .

\section{CUADRO 3. VARIABLES USADAS EN EL ANÁLISIS FACTORIAL}

1. Porcentaje de población menor de 15 años respecto al total.

2. Porcentaje de población de más de 64 años respecto al total.

3. Porcentaje de población de 20 a 34 años respecto al total.

4. Porcentaje de jornaleros respecto al total de población activa.

5. Porcentaje de propietarios, rentistas e industriales respecto al total de población activa.

6. Porcentaje de sirvientes respecto al total de población activa.

7. Porcentaje de trabajadores manuales de la industria y la construcción respecto al total de población activa.

8. Porcentaje de categorías profesionales más cualificadas (números $6,7,8$ y $9 \mathrm{del}$ apartado profesiones) respecto al total de la población activa.

9. Porcentaje de población nacida en Burgos capital respecto al total de la población.

10. Porcentaje de población nacida fuera de la provincia respecto al total de la población.

11. Porcentaje de analfabetos respecto a la población total.

12. Porcentaje de población no nacida en la capital y residente en ella más de 15 años respecto a la población total.

13. Porcentaje de población no nacida en la capital y residente en ella de 1 a 5 años respecto al total de la población.

14. Porcentaje de población activa respecto a la población total.

15. Porcentaje de profesiones liberales, procuradores, magistrados respecto al total de la población activa.

16. Porcentaje de solteros respecto a la población total.

Como vemos, hemos seleccionado 16 variables que podemos agrupar en estos grandes grupos:

A) Variables que reflejan la estructura de la población residente: 1, 2, 3 y 16.

B) Variables que reflejan el nivel educativo: 11. 
C) Variables que reflejan la procedencia de la población: 9, 10, 12 y 13.

D) Variables que reflejan la situación, respecto a la actividad económica y el nivel profesional: 4, 5, 6, 7, 8, 14 y 15 .

Las variables referidas a la estructura de la población recogen los tramos de edad que son más significativos y representativos del total de la población. En este sentido, los extremos de la pirámide, jóvenes y mayores, son indicadores especialmente interesantes para conocer el perfil poblacional.

La variable que refleja el nivel educativo se ha quedado en única, ya que el PMH no recoge ningún dato más a este respecto. Hubiera sido interesante tener la posibilidad de profundizar en este sentido, pues el nivel educativo suele ser fiel reflejo del social.

Las variables que reflejan la procedencia de la población resultan significativas, debido al importante número de residentes en la ciudad que no han nacido en ella. Respecto a la población emigrada, señalamos dos umbrales importantes. El primero se refiere a la población llegada antes de 1930 y el segundo se refiere a la población emigrada tras la reciente Guerra Civil.

De las variables relacionadas con la actividad y nivel profesional, los dos primeros grupos son de uso normal en estudios que tienen como fuente el $\mathrm{PMH}$. En el tercer grupo se añade una novedad importante. El tipo de recogida de la información permite obtener desagregadas unas variables que no hemos encontrado en ningún trabajo de este tipo, como son las de jornaleros y sirvientes. Con jornalero, el PMH se refiere de forma genérica a situaciones laborales variadas, como no tener un empleo fijo, ser peón en varios ramos de actividad, especialmente construcción, y estar parado algunos meses del año, sobre todo en invierno, lo que nos lleva al último escalón dentro del mundo laboral. Cobra mayor significado al ver los porcentajes que alcanza dentro de la población activa, con una media en la ciudad del $25,6 \%$, llegando en secciones a superar el $50 \%$. Por sirviente se entiende la empleada de hogar o criada interna en casa de la familia a la que sirve. Sus porcentajes también son muy altos, con el $11,3 \%$ del total de la población activa y casi el $47,7 \%$ del total de las mujeres activas. C. DELGADO nos habla de estas dos categorías laborales ya tremendamente significativas en los padrones de principio de siglo a la vez que corrobora la precariedad del empleo del jornalero (DELGADO VIÑAS, C, 1993, págs. 27-33). Estos altísimos porcentajes de jornaleros y sirvientes nos tienen que situar dentro de un mundo laboral muy en precario, difícilmente de imaginar solamente con porcentajes.

Los valores de las variables seleccionadas para el análisis vienen recogidas en el cuadro 4. 
La diferenciación socio-espacial en la ciudad de Burgos durante los años ...

CUADRO 4. MATRIZ INICIAL (VARIABLES X LUGARES) PARA LA REALIZACIÓN DEL ANÁLISIS FACTORIAL

\begin{tabular}{|c|c|c|c|c|c|c|c|c|}
\hline & \multicolumn{8}{|c|}{ VARIABLES } \\
\hline & 1 & 2 & 3 & 4 & 5 & 6 & 7 & 8 \\
\hline \multicolumn{9}{|l|}{ ZONA } \\
\hline 1 & 21,2 & 8,2 & 23,7 & 16,5 & 22,4 & 17,5 & 8,2 & 5,9 \\
\hline 2 & 23,3 & 6,7 & 23,3 & 8,8 & 16,1 & 26,4 & 6,5 & 11,6 \\
\hline 3 & 23 & 9,8 & 27,8 & 22,9 & 10,4 & 17,7 & 6 & 7,8 \\
\hline 4 & 19,6 & 7,7 & 16,1 & 20,9 & 3,5 & 14,1 & 16 & 8,8 \\
\hline 5 & 17,9 & 8,7 & 29,3 & 14,8 & 7,4 & 20,9 & 9,6 & 19,5 \\
\hline 6 & 15,4 & 11,2 & 34,9 & 8 & 10,4 & 19,7 & 8 & 14,4 \\
\hline 7 & 22,4 & 5,4 & 26,9 & 16,4 & 8,9 & 8,9 & 17 & 8,1 \\
\hline 8 & 26,6 & 6,8 & 27,6 & 20,7 & 15,8 & 15,8 & 7,9 & 4,9 \\
\hline 9 & 32,8 & 6,3 & 22,6 & 9,7 & 4,7 & 40,3 & 10,5 & 13,5 \\
\hline 10 & 25,8 & 6,5 & 27,2 & 33,7 & 6,7 & 13,5 & 14,9 & 5,2 \\
\hline 11 & 37 & 3,3 & 23,1 & 38,9 & 1,8 & 3,6 & 22,8 & 3,6 \\
\hline 12 & 30,1 & 5,9 & 23,1 & 32,2 & 4,3 & 0 & 22,1 & 3 \\
\hline 13 & 34,5 & 4 & 22 & 51,5 & 0 & 1,6 & 9,4 & 3,1 \\
\hline 14 & 26,9 & 6,1 & 26,2 & 43,8 & 6,6 & 2,3 & 15,3 & 3,3 \\
\hline 15 & 32,6 & 5 & 25,9 & 41,3 & 0,6 & 0 & 38,7 & 5 \\
\hline 16 & 29,7 & 4,1 & 26 & 31,9 & 6 & 5,5 & 23,5 & 4,4 \\
\hline 17 & 32,8 & 4,3 & 23,3 & 8 & 13,3 & 30,6 & 10,5 & 1,2 \\
\hline 18 & 27,8 & 7 & 25,7 & 28,6 & 2,7 & 10,4 & 18,2 & 7,7 \\
\hline 19 & 33,1 & 1,5 & 27,4 & 4,3 & 4,4 & 31 & 11,1 & 6,7 \\
\hline 20 & 30,2 & 2,8 & 27,2 & 12,2 & 3 & 8,6 & 28,4 & 9,8 \\
\hline 21 & 44,7 & 4,7 & 29,8 & 17,7 & 8,9 & 9,9 & 15,6 & 8,9 \\
\hline 22 & 36,2 & 5,8 & 23,3 & 53,6 & 1,1 & 0 & 6,8 & 1,1 \\
\hline 23 & 26,1 & 7,6 & 29,3 & 22,6 & 9,9 & 6,5 & 27,2 & 2,8 \\
\hline 24 & 26,8 & 4,2 & 31 & 14,8 & 10,3 & 16,7 & 11,1 & 16,7 \\
\hline 25 & 25,5 & 2,8 & 29,7 & 20,5 & 10,3 & 11,8 & 19 & 13,1 \\
\hline 26 & 26,1 & 8,8 & 27,3 & 24,3 & 9,8 & 15,9 & 15,9 & 4,9 \\
\hline 27 & 29,6 & 4,5 & 31,1 & 34,2 & 2,3 & 8,5 & 14,6 & 14,6 \\
\hline 28 & 25,9 & 5,7 & 28,7 & 24,4 & 5 & 11,6 & 21,6 & 3,4 \\
\hline 29 & 25,2 & 5,3 & 25,9 & 16,1 & 3,2 & 10,5 & 30,1 & 10,5 \\
\hline 30 & 35,3 & 2,7 & 26,6 & 30,3 & 1,8 & 5 & 22,5 & 10,4 \\
\hline 31 & 35,9 & 4,3 & 17,7 & 50 & 0 & 11 & 14 & 0 \\
\hline 32 & 25,5 & 8,8 & 25,5 & 9,1 & 8,1 & 15 & 24,4 & 10,6 \\
\hline 33 & 26,5 & 1,8 & 26 & 33,4 & 5,1 & 3,9 & 32 & 2,5 \\
\hline 34 & 31,1 & 1,9 & 28,4 & 39,7 & 2,3 & 0 & 46,8 & 1,2 \\
\hline 35 & 28,6 & 6,2 & 26 & 33,4 & 8,2 & 5,7 & 30,6 & 2,8 \\
\hline 36 & 40,1 & 3,1 & 19,8 & 48,9 & 0,9 & 1,8 & 28,4 & 4,6 \\
\hline
\end{tabular}


CUADRO 4. MATRIZ INICIAL (VARIABLES X LUGARES) PARA LA REALIZACIÓN DÉL ANÁLISIS FACTORIAL (continuación)

\begin{tabular}{|c|c|c|c|c|c|c|c|c|}
\hline & \multicolumn{8}{|c|}{ VARIABLES } \\
\hline & 9 & 10 & 11 & 12 & 13 & 14 & 15 & 16 \\
\hline \multicolumn{9}{|c|}{ ZONA } \\
\hline 1 & 53,4 & 16 & 1,8 & 38,6 & 25,5 & 38,8 & 2,3 & 63,5 \\
\hline 2 & 54,4 & 15,5 & 0,5 & 38,3 & 26,2 & 35,2 & 6 & 58,5 \\
\hline 3 & 47 & 17,8 & 3 & 39,1 & 28 & 38,3 & 2,6 & 59,3 \\
\hline 4 & 53 & 11,9 & 3 & 58,2 & 7 & 33,9 & 1,8 & 53,6 \\
\hline 5 & 48,9 & 15,8 & 2,7 & 43,3 & 29 & 36,4 & 3 & 58,7 \\
\hline 6 & 40,2 & 24,9 & 0,6 & 36,6 & 11,9 & 45 & 6,7 & 56,8 \\
\hline 7 & 48,3 & 19,1 & 1,4 & 32,6 & 26,4 & 34,7 & 2 & 59,7 \\
\hline 8 & 59,4 & 12,5 & 1,6 & 43,1 & 17,4 & 32,7 & 0 & 59,9 \\
\hline 9 & 44,6 & 30,7 & 0,7 & 20,7 & 32,6 & 36,2 & 8,7 & 66,6 \\
\hline 10 & 44,2 & 17,5 & 0,9 & 41 & 17,4 & 34,1 & 1,5 & 57,1 \\
\hline 11 & 47,4 & 18,5 & 3,5 & 41,2 & 23,7 & 32,9 & 0 & 60,1 \\
\hline 12 & 53,8 & 18,3 & 0 & 35,5 & 29,6 & 36,6 & 0 & 54,8 \\
\hline 13 & 41 & 20 & 2 & 24,4 & 39,7 & 32 & 0 & 55,5 \\
\hline 14 & 53,3 & 13,4 & 2 & 47,7 & 19,7 & 30,1 & 0 & 54,4 \\
\hline 15 & 47,5 & 17,3 & 0,5 & 37,9 & 16,1 & 34,1 & 0 & 58 \\
\hline 16 & 49,5 & 17 & 1,4 & 32,9 & 42,2 & 36,6 & 0,5 & 57,1 \\
\hline 17 & 44,8 & 31,5 & 1,3 & 28,8 & 46 & 32,3 & 0 & 61,6 \\
\hline 18 & 46,1 & 22,2 & 1,3 & 41,7 & 23,6 & 33,5 & 0 & 61,7 \\
\hline 19 & 27 & 44,9 & 1,1 & 4,5 & 68,2 & 34,2 & 5,9 & 59,3 \\
\hline 20 & 41,9 & 21,4 & 1 & 27 & 35,5 & 32,7 & 0 & 57,1 \\
\hline 21 & 32,6 & 29,3 & 9,6 & 18,6 & 43,5 & 28,2 & 0 & 53,3 \\
\hline 22 & 65,4 & 4,2 & 1 & 26,8 & 32,4 & 27,8 & 1,1 & 55 \\
\hline 23 & 45,5 & 16,4 & 3,5 & 33,9 & 29 & 32,3 & 0 & 55,4 \\
\hline 24 & 33,5 & 27,5 & 1,1 & 15,5 & 42,3 & 37,7 & 1,9 & 58,5 \\
\hline 25 & 50,5 & 21,2 & 0 & 40,6 & 29,3 & 32,1 & 1,6 & 59,4 \\
\hline 26 & 45,8 & 16 & 2,9 & 37,5 & 25,6 & 34,5 & 0 & 57,1 \\
\hline 27 & 49,8 & 13,1 & 0,7 & 28,1 & 40,9 & 30,7 & 0 & 60,7 \\
\hline 28 & 45,4 & 18,1 & 0,9 & 26,6 & 30 & 31,9 & 0 & 58 \\
\hline 29 & 48 & 17,1 & 1,2 & 43,6 & 28,2 & 37,2 & 0,6 & 61,7 \\
\hline 30 & 35,2 & 24,9 & 1,4 & 20,2 & 53,1 & 28 & 0 & 56,1 \\
\hline 31 & 56,4 & 1,7 & 1,7 & 21,2 & 61,7 & 30,8 & 0 & 63,2 \\
\hline 32 & 34,7 & 31 & 0 & 26,8 & 32,4 & 36 & 2,2 & 62,3 \\
\hline 33 & 40,2 & 21 & 0,9 & 26,4 & 29,5 & 35,6 & 0 & 58 \\
\hline 34 & 31,1 & 14,8 & 0,4 & 18,5 & 44,8 & 34,2 & 0 & 57,2 \\
\hline 35 & 38,3 & 26,6 & 1,3 & 32,8 & 32,2 & 31,7 & 1,2 & 61,2 \\
\hline 36 & 37 & 21 & 5,6 & 25,2 & 38,7 & 32,7 & 0,9 & 63,6 \\
\hline
\end{tabular}




\subsection{Análisis de los resultados}

Con las 16 variables introducidas, tras hallar los factores y hacer la rotación de la matriz de resultados, obtenemos que los cuatros factores primeros explican el $72,5 \%$ de la varianza, como se recoge en el cuadro 5 , siendo la explicación del resto de los factores mínima.

\section{CUADRO 5. PORCENTAJE DE EXPLICACIÓN DE LOS CUATROS PRIMEROS FACTORES}

\begin{tabular}{lrr} 
& PORCENTAJE & PORCENTAJE ACUMULADO \\
\hline Factor 1 & 31,1 & 31,1 \\
Factor 2 & 22,5 & 53,6 \\
Factor 3 & 11,6 & 65,2 \\
Factor 4 & 7,3 & 72,5 \\
\hline
\end{tabular}

La correlación de estos 4 factores con las 16 variables elegidas vienen recogidas en el cuadro 6 .

CUADRO 6. MATRIZ FACTORIAL

\begin{tabular}{|c|c|c|c|c|}
\hline FACTOR & 1 & 2 & 3 & 4 \\
\hline \multicolumn{5}{|l|}{ NÚMERO DE LA VARIABLE } \\
\hline $1 \%$ población menor de 15 años & $-0,366$ & $-0,78$ & $-0,018$ & 0,354 \\
\hline $2 \%$ población mayor de 64 años & 0,364 & 0,726 & $-0,227$ & $-0,004$ \\
\hline $3 \%$ población de 20 a 34 años & 0,157 & 0,148 & 0,31 & $-0,763$ \\
\hline $4 \%$ jornaleros de población activa & $-0,802$ & $-0,155$ & $-0,211$ & 0,301 \\
\hline $5 \%$ propietarios, rentistas de po.ac. & 0,558 & 0,34 & $-0,219$ & $-0,209$ \\
\hline $6 \%$ sirvientes de población activa & 0,939 & $-0,06$ & $-0,071$ & 0,055 \\
\hline $7 \%$ trabajadores indust./const. de p.a. & $-0,61$ & $-0,018$ & 0,656 & 0,056 \\
\hline $8 \%$ profesionales cualificados de p.a & 0,571 & 0,217 & 0,173 & $-0,315$ \\
\hline $9 \%$ población nacida en la capital & $-0,136$ & 0,378 & $-0,816$ & 0,172 \\
\hline $10 \%$ población nacida fuera provincia & 0,52 & $-0,363$ & 0,584 & $-0,163$ \\
\hline $11 \%$ analfabetos del total población & $-0,153$ & 0,179 & 0,002 & 0,644 \\
\hline $12 \%$ pobla. no capital residiendo +15 a. & $-0,138$ & 0,853 & $-0,289$ & 0,138 \\
\hline $13 \%$ pobla no capital residiendo 1 a 5 a. & 0,071 & $-0,894$ & 0,101 & $-0,002$ \\
\hline $14 \%$ población activa del total & 0,51 & 0,553 & 0,361 & 0,029 \\
\hline $15 \%$ profesiones liberales de poc. ac. & 0,825 & 0,059 & 0,075 & 0,05 \\
\hline $16 \%$ solteros de población total & 0,474 & $-0,139$ & 0,149 & 0,584 \\
\hline
\end{tabular}


El primer factor resultante explica el $31,1 \%$ de la varianza y tiene una fuerte correlación positiva con las profesiones liberales y sirvientes, siendo algo menor con los industriales y las categorías profesionales más cualificadas. Por otro lado, presenta una fuerte correlación negativa con jornaleros y trabajadores manuales. Como vemos, es un claro factor social, donde se polarizan los estratos sociales más y menos favorecidos. A este factor le llamaremos SOCIAL. Hay que señalar la importancia de este factor por tener unas claras connotaciones sociales, esenciales en estudios de segregación urbana y por su alto grado de explicación.

El segundo factor resultante explica el $22,5 \%$ de la varianza. Tiene una correlación positiva elevada con los inmigrantes con más de 15 años de residencia en la capital y en menor medida con la población activa. Tiene una correlación negativa con los inmigrados que llevan en la ciudad menos de quince años. Podemos concluir de estos datos que correlaciona una población inmigrada desde hace tiempo, pero asentada perfectamente en la ciudad con otra población emigrada tras la Guerra Civil, mucho más jóven y no asentada laboralmente en la ciudad. Este factor le llamaremos EMIGRACIÓN.

El tercer factor explica el $11,6 \%$ de la varianza. Tiene una correlación positiva con el apartado de las profesiones referido a los trabajadores manuales de la industria y la construcción y en menor medida con los residentes nacidos fuera de la provincia. Su correlación negativa tiene con los residentes nacidos en la ciudad nos informa de una población burgalesa que obtiene su empleo en sectores ajenos al secundario manual. Este factor le llamaremos LEJANÍA.

Finalmente, el cuarto factor explica el $7,3 \%$ de la varianza. Tiene correlación con variables de carácter heterogéneo. Positiva con el porcentaje de analfabetos y solteros, negativa con la población de residente de 20 a 34 años. A este factor le llamaremos VARIADO.

Como vemos, la segregación que resulta en la ciudad tiene una clara relación con el estatus social de los residentes, polarizándose significativamente en los extremos. Los componentes relacionados con los grupos de edad y estado civil casi no cobran relevancia.

\subsection{Las notaciones factoriales y su distribución diferencial en la ciudad. Principales pautas de la diferencia social urbana}

La distribución espacial de las notaciones factoriales de los primeros cuatro factores resultan decisivas para intentar explicar la diferenciación 
La diferenciación socio-espacial en la ciudad de Burgos durante los años ...

socioespacial de la ciudad. Los valores resultantes vienen recogidos en el cuadro 7.

CUADRO 7. DISTRIBUCIÓN ESPACIAL DE LAS NOTACIONES

FACTORIALES

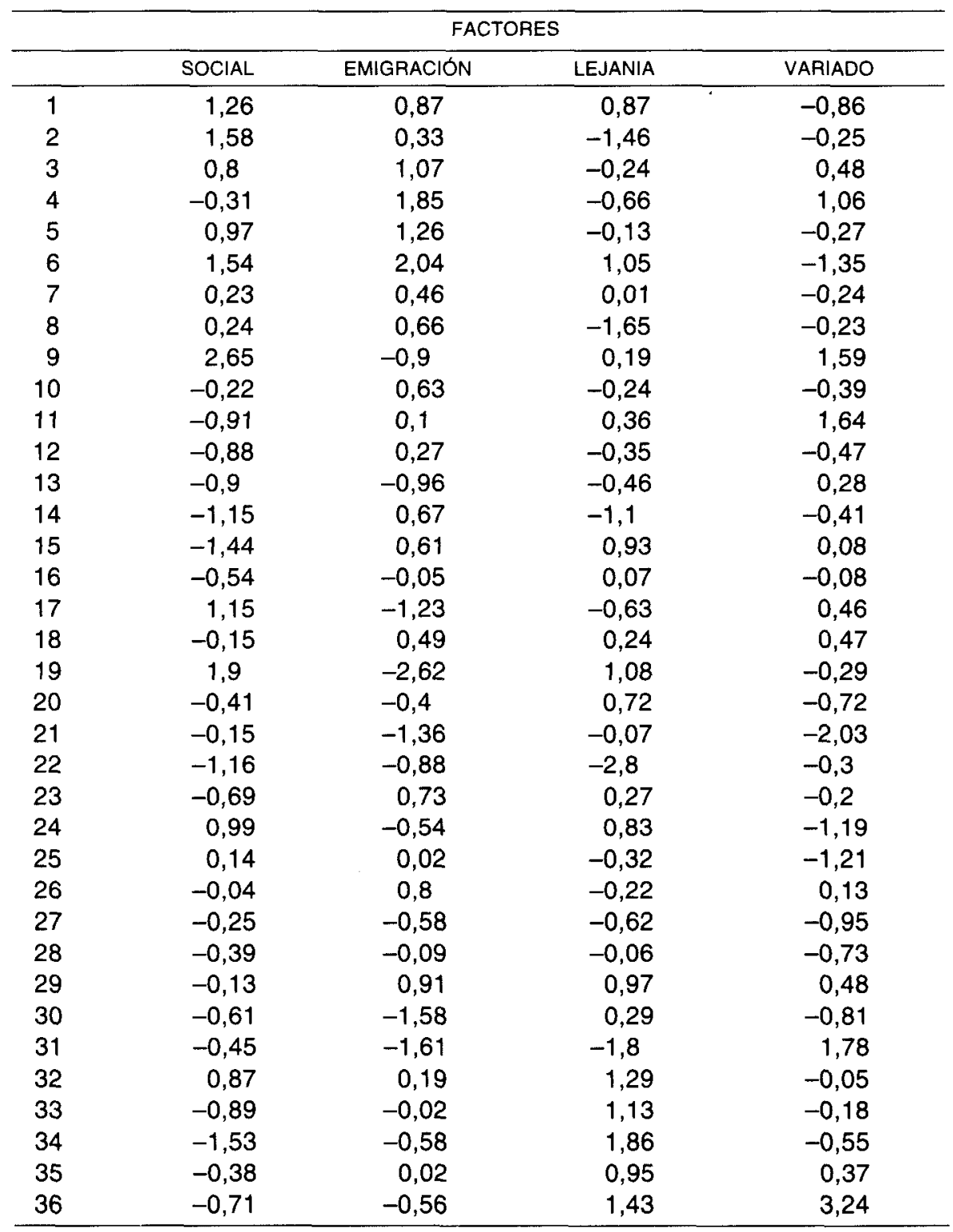


Hemos agrupado los resultados resultantes relativos a cada factor en cuatro grupos según la escala presentada en el cuadro 8.

CUADRO 8. CRITERIOS DE ZONIFICACIÓN HOMOGÉNEA DE LAS NOTACIONES FACTORIALES

\begin{tabular}{lc}
\hline 1 & inferior a $-0,75$ \\
2 & de $-0,75$ a 0 \\
3 & de 0 a 0,75 \\
4 & superior a 0,75 \\
\hline
\end{tabular}

Ello nos da como resultado final cuatro planos de la ciudad donde se encuentran trasladados los resultados de los 4 factores obtenidos.

* El primer factor nos da los resultados según número de zonas recogidas en el cuadro 9:

CUADRO 9. NÚMERO DE ZONAS SEGÚN CATEGORÍAS (FACTOR 1)

\begin{tabular}{rcr}
\hline \multicolumn{3}{c}{ FACTOR 1} \\
\hline 1 & & N. ${ }^{\circ}$ DE ZONAS \\
\hline 2 & inferior a $-0,75$ & 9 \\
3 & de $-0,75$ a 0 & 14 \\
4 & de 0 a 0,75 & 3 \\
\hline
\end{tabular}

Estas zonas quedan reflejadas en el plano de la ciudad según vemos en la figura 5.

Destacamos la polarización numérica existente en los extremos, lo que nos habla de grupos sociales separados de forma significativa.

El grupo del número 1, las zonas menos favorecidas de la ciudad se encuentran en la zona elevada del Casco Antiguo (14 y 15), situada en las laderas del cerro del Castillo. Otra zona claramente marcada de forma negativa es el barrio de San Pedro de la Fuente (11, 12 y 13). También aparece la zona de San Pedro y San Felices (33 y 34) y el triángulo que cierra la calle Concepción. La zona 22 aparece también, pero es una zona heterogénea en la que se recoge la población de los barrios limitrofes claramente rurales. En estas zonas es donde vive la población de la ciudad que reúne las peores condiciones socioeconómicas. 


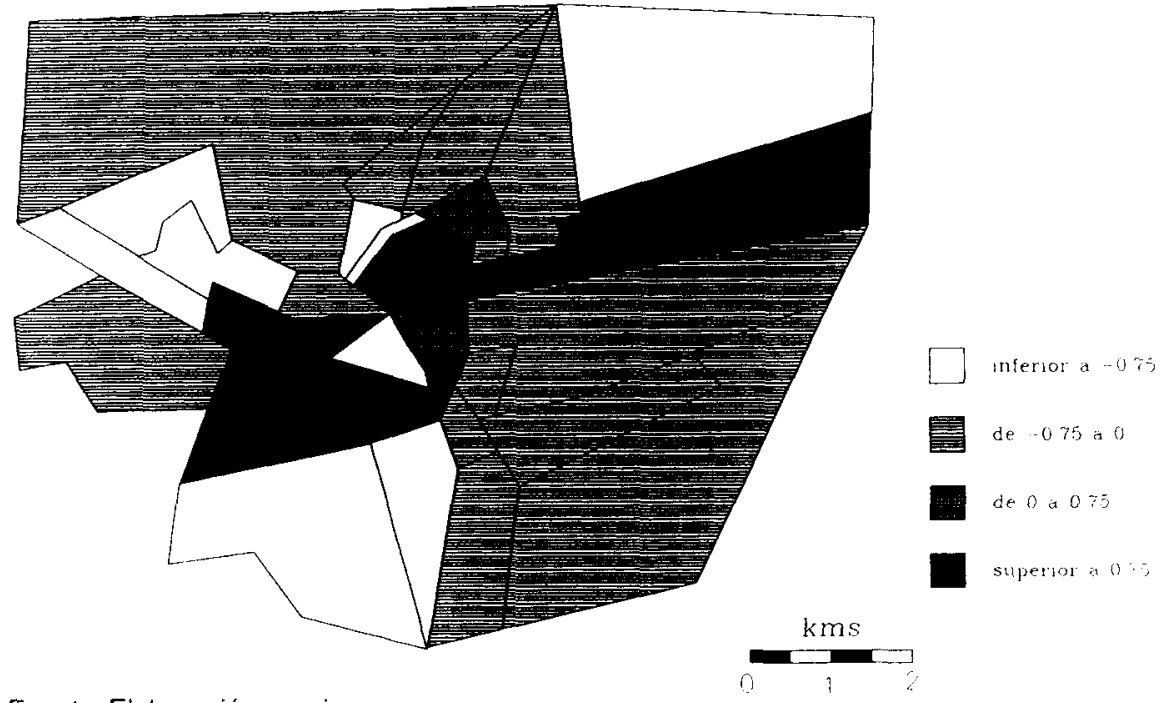

Fuente: Elaboración propia.

Figura 5. Distribución espacial de las notaciones factoriales. Factor 1. Burgos 1945.

Las zonas más favorecidas serían las pertenencientes al centro urbano $(1,2,3,5$ y 6$)$, la zonas al margen de la calle Vitoria cercanas al centro ( 17 y 19), junto con la zona 9 , zona contigua a la Audiencia y antiguo ensanche burgués, la zona 32 , que engloba la zona residencial de la Castellana y la zona 24, en la parte sur de la ciudad, potenciada por la ubicación de la Estación de Autobuses y los intentos de hacer un nuevo centro urbano.

* El segundo factor nos da los resultados en número de zonas recogidas en el cuadro 10:

CUADRO 10. NÚMERO DE ZONAS SEGÚN CATEGORÍAS (FACTOR 2)

\begin{tabular}{rrr}
\hline \multicolumn{3}{c}{ FACTOR 2 } \\
\hline 1 & & N.. DE ZONAS \\
2 & inferior a $-0,75$ & 8 \\
3 & de $-0,75$ a 0 & 8 \\
4 & de 0 a 0,75 & 13 \\
\hline
\end{tabular}

Trasladados los resultados a las zonas de la ciudad obtenemos los resultados recogidos en la figura 6 . 


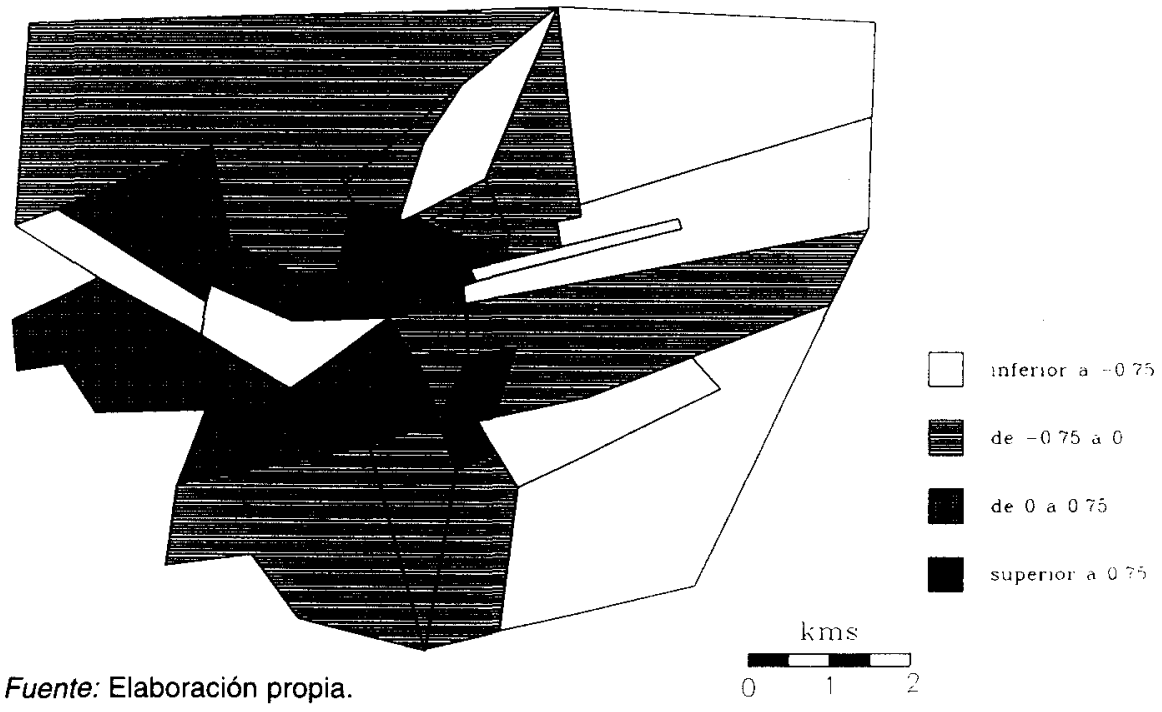

Figura 6. Distribución espacial de las notaciones factoriales. Factor 2. Burgos 1945.

Se aprecia que la polarización ha disminuido con respecto al Factor 1. No obstante, siguen existiendo un buen número de zonas colocadas en los extremos de la tabla. Por zonas, siguen con un rango netamente positivo el Centro de la ciudad $(1,3,4,5$ y 6 ), salvo la zona 2 , que ha variado un poco. En el extremo negativo, aparecen zonas periféricas en San Pedro de la Fuente (13), en San Julián (30 y 31) junto con las zonas $17,19,21$ y 22 en la zona de Vadillos, por entonces, el Ensanche de la ciudad. El resto de zonas intermedias se distribuyen de forma heterogénea por la ciudad.

* El tercer factor nos arroja la tabla recogida en el cuadro 11, según el número de zonas:

CUADRO 11. NÚMERO DE ZONAS SEGÚN CATEGORÍAS (FACTOR 3)

\begin{tabular}{rcr}
\hline \multicolumn{3}{c}{ FACTOR 3 } \\
\hline 1 & N. DE ZONAS \\
\hline 2 & inferior a $-0,75$ & 5 \\
3 & de $-0,75$ a 0 & 12 \\
4 & de 0 a 0,75 & 8 \\
\hline
\end{tabular}


Al igual que los factores anteriores, presentamos los resultados trasladados al plano de la ciudad, recogidos en la figura 7.

Este factor adquiere una distribución en la ciudad mucho más heterogénea que los dos primeros, por lo que resulta difícil establecer zonas significativas. Sí se aprecia que el componente relacionado con la población no emigrada y no vinculado al sector secundario encuentra su mayor acomodo en las centrales $(2,14$ y 8$)$ y dos zonas periféricas vinculadas a los barriospueblos de Villimar y Cortes. Al extremo opuesto del factor, vemos que la mayoría de las zonas se encuentran ubicadas en el Sur de la ciudad. dro 12:

* El factor 4 nos da los resultados según zonas recogidas en el cuaCUADRO 12. NÚMERO DE ZONAS SEGÚN CATEGORÍAS (FACTOR 4)

\begin{tabular}{rcr}
\hline \multicolumn{3}{c}{ FACTOR 4} \\
\hline 1 & & N. DE ZONAS \\
2 & inferior a $-0,75$ & 7 \\
3 & de $-0,75$ a 0 & 16 \\
4 & de 0 a 0,75 & 8 \\
\hline
\end{tabular}

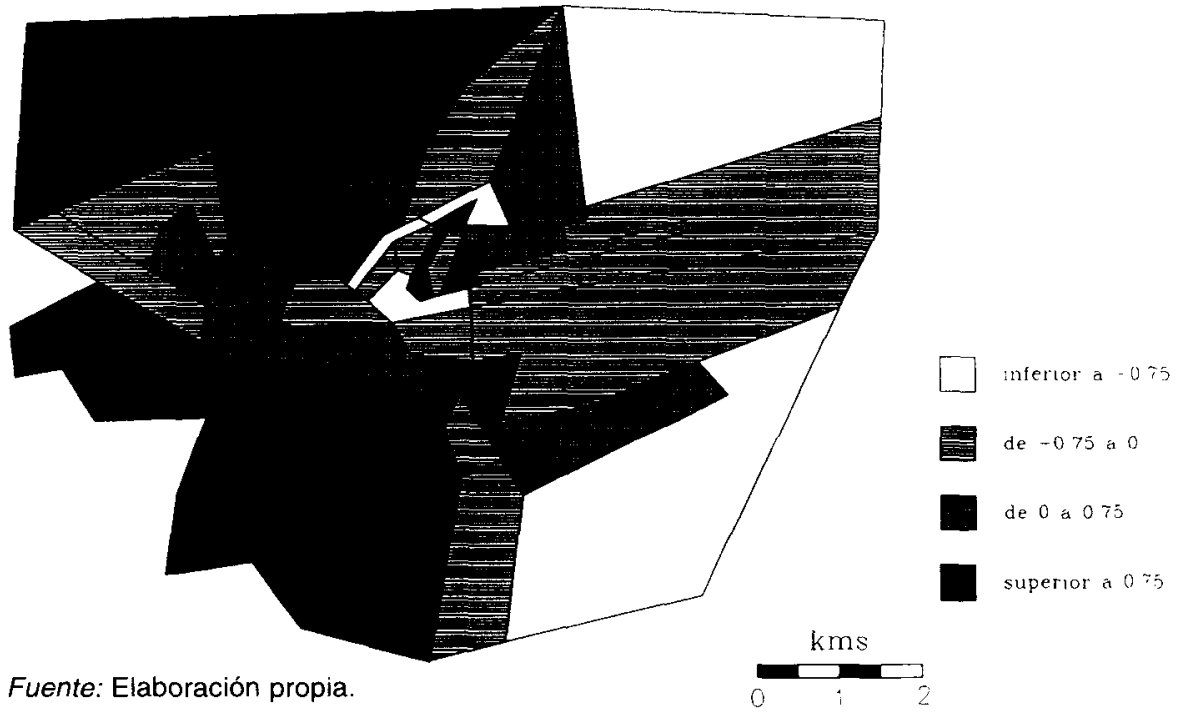

Figura 7. Distribución espacial de las notaciones factoriales. Factor 3. Burgos 1945. 
En la figura 8 recogemos los resultados de este factor trasladados al plano de zonas de la ciudad.

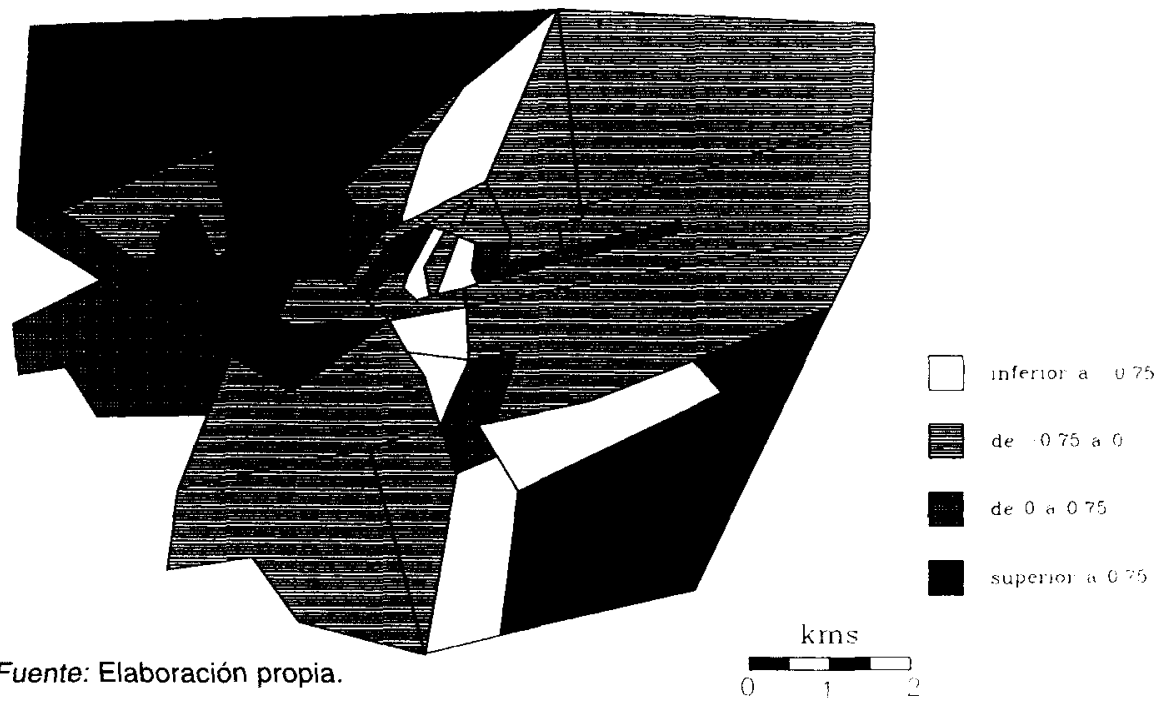

Figura 8. Distribución espacial de las notaciones factoriales. Factor 4. Burgos 1945.

Este factor no nos marca sectores homogéneos en la ciudad, sino que se reparte de forma irregular, dando un resultado heterogéneo.

* Como resumen, podemos afirmar que son los dos primeros factores los que nos muestran de forma clara la segregación socioespacial existente en la ciudad. La zona con un mayor estatus social estaría claramente ubicada en el Centro de la ciudad $(1,2,3,4,5$, y 6$)$ y las zonas menos favorecidas se ubicarian en la zona de la ladera de El Castillo ( 14 y 15), zonas de San Pedro de la Fuente $(11,12$ y 13) y la zona de San Pedro y San Felices (34 y 35).

Los problemas de segregación socioespacial de estas zonas ya es señalado por el Gobernador Civil de la ciudad en 1940, cuando en el nombramiento del "primer Ayuntamiento de la paz", hace hincapié en el grave problema existente en la ciudad: "Hay dos barrios en Burgos en los que viven más de cuatro mil burgaleses: el barrio de San Esteban y el de San Pedro de la Fuente, que no tienen casas en condiciones higiénicas de habitabilidad, que no poseen conducciones de agua y apenas si gozan del servicio de alcantarillado. $Y$ estos cuatro mil burgaleses viven en casas sórdidas..." ${ }^{4}$.

4 Pleno Municipal, 27-5-40, folios $137-139$. 
Con un argumento parecido se explica el alcalde de la ciudad en 1945, Carlos Quintana Palacios en una entrevista realizada por la prensa local. Tras señalar la falta clara de vivienda para las clases humildes, dando la cifra de 2.500 familias viviendo en casas insalubres y citando el barrio de San Esteban como ubicación primordial de las mismas ${ }^{5}$.

\section{CONCLUSIONES}

\subsection{Una ciudad con una clara segregación socioespacial}

El objetivo principal propuesto, descubrir si existía segregación socioespacial en la ciudad ha dado un resultado positivo. Se ha expuesto con claridad que la ciudad no era en 1945 un todo homogéneo. Existian contrastes manifiestos entre unas zonas favorecidas y otras más problemáticas.

Los grupos dominantes estaban asentados en las zonas más céntricas de la ciudad, lugar de ubicación de las principales instituciones y las funciones terciarias elevadas. El prestigio de vivir en el «centro» era un elemento fundamental.

Los grupos menos favorecidos se hallaban establecidos en la periferia, alejados del centro de la ciudad y en las laderas del cerro del Castillo, la parte más antigua existente, que habia sufrido un proceso de deterioro continuado durante siglos, desde que el centro funcional de la ciudad se trasladó al llano cercano al río Arlanzón. Desde entonces y hasta hoy, esta sería la zona más deteriorada de la ciudad.

4.2. Resultados positivos como la fuente usada y el método estadístico elegido

El PMH es una fuente esencial a la hora de conocer la población de una ciudad por las condiciones que reúne. A nosotros nos ha permitido radiografiar una ciudad muy ajena a la actual. Difícilmente se puede encontrar otra fuente para llegar a estos conocimientos.

5 Diario de Burgos, 27-5-45, pág. 1 
La técnica estadística usada, el análisis factorial, nos ha permitido sintetizar en muy pocos factores, esencialmente en dos, las múltiples variables que se han barajado.

\section{BIBLIOGRAFÍA}

Aguilera Arilla, M. J. (1988): "Diferenciación del espacio social de Alcorcón». Estudios Geográficos, Tomo XLX, n. 190, pp. 5-28.

Álvarez-Cienfuegos Ruiz, F.J. (1984): “El proceso de urbanización en España y sus condicionamientos estructurales, 1940-1981». Estudios Territoriales, n. ${ }^{2} 11-12$, pp. 105-125.

ÁvILA TAPIES, R. (1993): "Nuevas perspectivas de las emigraciones interiores españolas". Anales de Geografía de la Universidad Complutense, n. 912 , pp. 111-126.

BARBANCHO, A.G. (1987): Las migraciones interiores españolas desde 1900. Edita Instituto de Desarrollo Económico. Madrid.

Cañamero, A. (1988): “Alza. Crecimiento urbano y demográfico de la periferia de San Sebastián», Lurralde, n. 11, pp. 219-285.

DELGADO VIÑAS, C. (1993): Clase obrera, burguesia y conflicto social. Burgos, 1883-1936. Edita Secretariado de Publicaciones de la Universidad de Valladolid.

DiAz Muñoz, M. A. (1986): "Alcalá de Henares: la diferenciación residencial en una ciudad histórica del área metropolitana de Madrid", Anales de Geografia de la Universidad Complutense, n. 6 , pp. 253-272.

Díaz MuÑoz, M.” A. (1989): "Hacia un modelo de diferenciación residencial urbana en España. La aportación del análisis de áreas sociales y la ecología factorial", Estudios Territoriales, n. ${ }^{\circ} 31$, pp. 115-133.

Fernández GutiérRez, F. (1977): “Aplicaciones de la técnica factorial en el estudio geográfico del área urbana de Granada", Cuadernos Geográficos de la Universidad de Granada,.$^{\circ} 7$, pp. 197-269.

García Ballesteros, A. (1978): Geografía urbana de Guadalajara. Edita Fundación Universitaria Española. Madrid.

GONZÁLEZ, N. (1958): Burgos. La ciudad marginal de Castilla.

Gómez FAyren, J., BEL ADELL, C. (1987): "Aproximación a la diferenciación social del espacio urbano en la ciudad de Murcia", Anales de Geografia de la Universidad Complutense, n. ${ }^{\circ} 7$, pp. 421-428.

González Gonzalez, M. J. (1987): Diferenciación socioeconóica en la ciudad de León. Servicio de Publicaciones de la Universidad de León. Junta de Castilla y León.

JiMÉnEZ, M. J. (1990): Espacio urbano y sociedad. Estudio del Padrón Municipal de Zaragoza de 1857. Edita Institución Fernando el Católico. Zaragoza.

JIMÉNEZ BLASCO, B.C. (1984): "Aproximación metodológica al estudio de la diferenciación residencial urbana en Madrid». Anales de Geografia de la Universidad Complutense, n. ${ }^{4}$, pp. 167-183.

Leonardo aurtenetXe, J.J., Lavia Martínez, C. (1990): “Hacia un modelo de diferenciación residencial: análisis comparativo de Bilbao y Vitoria-Gasteiz". Ciudad y Territorio, n. ${ }^{\circ} 83, \mathrm{pp}$. 97-109.

MAC ELRATH, D.C. (1962): «The Social areas of Rome: A comparative analysis". American sociological Review, pp. 376-391.

MORENo JiméneZ, A. (1987): "La diferenciación social del espacio en Carabanchel». Anales de Geografía de la Universidad Complutense, n. ${ }^{\circ} 7$, pp. 471-479.

Ortiz Alejos, F. (1989): La diferenciación social del espacio urbano de Logroño. Instituto de Estudios Riojanos.

Puyol, R., Estébanez, J., MÉndez, R. (1992): Geografia Humana. Edit. Cátedra. Madrid.

Precedo, A., Rodriguez-Martinez, R., Villarino, M. (1989): Vigo. Área metropolitana. Edit., Universidad de Santiago. Fundación Caixa Galicia. 
Rios IVARS, J., ELIZALDE, J. (1979): "Análisis del funcionamiento espacial del equipamiento en el Área Metropolitana de Madrid". Ciudad y Territorio, n. ${ }^{\circ} 2$, pp. 51-54.

Santos Preciado, J.M. (1988): El modelo de diferenciación residencial del sector suroeste del área metropolitana de Madrid. Edit. de la Universidad Complutense de Madrid.

SANTOS PRECIADO, J.M. (1991): "La técnica factorial y sus aplicaciones en el campo geográfico". Espacio, Tiempo y Forma. Serie VI, Geografía, tomo IV, pp. 13-70.

SWEETZER, G. (1960): «Factorial ecology: Helsinki: 1960», Demography, 2, pp. 372-386.

THEODORSON, G.A. (1974): Estudios de ecología humana. Edit. Labor. Barcelona.

TIMms, D. (1976): El mosaico urbano. Hacia una teoria de la diferenciación residencial. I.E.A.L. Madrid. 